This item was submitted to Loughborough's Research Repository by the author.

Items in Figshare are protected by copyright, with all rights reserved, unless otherwise indicated.

\title{
The additional cost of disability: a new measure and its application to sensory impairment
}

PLEASE CITE THE PUBLISHED VERSION

http://dx.doi.org/10.1080/09687599.2016.1221334

PUBLISHER

(c) Taylor \& Francis

VERSION

AM (Accepted Manuscript)

\section{PUBLISHER STATEMENT}

This work is made available according to the conditions of the Creative Commons Attribution-NonCommercialNoDerivatives 4.0 International (CC BY-NC-ND 4.0) licence. Full details of this licence are available at: https://creativecommons.org/licenses/by-nc-nd/4.0/

\section{LICENCE}

CC BY-NC-ND 4.0

\section{REPOSITORY RECORD}

Hirsch, Donald, and Katherine Hill. 2016. "The Additional Cost of Disability: A New Measure and Its Application to Sensory Impairment”. Loughborough University. https://hdl.handle.net/2134/22542. 


\title{
The additional cost of disability: a new measure and its application to sensory impairment
}

Donald Hirsch and Katherine Hill

\begin{abstract}
This article introduces a method using consensual budget standards to estimate additional costs incurred by households that include disabled people with specified impairments. It reports on a first application of this to UK single adults with sensory impairments. Using the Minimum Income Standard method, the research aims to identify the cost of disability by working with groups of disabled people to agree what additions to minimum budgets for nondisabled people are required for someone with a given impairment. This provides a more tangible account of the cost of disability than economic analysis of living standards achieved by disabled and non-disabled people, and adds to surveys of actual spending on additional items, which do not account for unmet need. The research on vision and hearing impairment yields new insights on costs arising from the way disabled people live their everyday lives, not just from spending on adaptations and equipment.
\end{abstract}

\section{Points of interest}

This article introduces a new way to measure the additional cost of living faced by disabled people. Such research can help inform public policies to help cover or to reduce these costs.

The method used here looks more directly than previous research at what people with particular impairments need to spend in order to achieve an acceptable living standard. It uses an approach, the Minimum Income Standard, that asks groups of members of the public about what things households need to buy to reach such a standard. In this case, it assembled groups of people with hearing loss and groups of people with different degrees of sight loss to assess what additional items people with these impairments require.

The research found that, in addition to occasional large outlays such as buying equipment, people who are vision impaired or profoundly deaf have significant extra day to day costs associated with how they live. These include extra domestic help, different kinds of travel and additional costs of social participation. 
Keywords:

Cost of disability

Deaf

Vision impairment

Minimum income 


\section{Introduction}

Disabled people often need to spend more on goods and services in order to meet an equivalent living standard to non-disabled people. This economic concept of "the additional cost of disability” has been important in assessing policies that direct extra resources to disabled people to help them meet these costs, or make other provision such as subsidising services that help reduce the costs that disabled people face (Stapleton et al, 2008, Corden et al, 2010). However, meaningful measures of the cost of disability have been hampered by difficulties in identifying what is "equivalence” and in specifying what kinds of additional spending are likely to achieve it. Reviews of research in this area (Morciano et al, 2012; Stapleton et al, 2008; Tibble, 2005; MacInnes et al, 2014) have concluded that while significant additional costs undoubtedly exist, they can be hard to measure accurately. This article reports on the results of a new methodology which uses a clear-cut definition to explore a range of additional costs faced by people in the United Kingdom with specified impairments, as identified by people who experience them. This technique uses the Minimum Income Standard (MIS) approach, a “budget standards” method developed in recent years to establish minimum requirements for non-disabled households (Bradshaw et al, 2008; Hirsch, 2015). Building on this baseline, the same method is used to calculate additional costs for disabled people, and thus improves on previous studies listing disabled people’s needs but lacking a reference point from which "additionality” can be established. The article draws on two studies applying this method to the additional costs of living for people with various types of sensory impairment. It explores how such a measure can shed light not only on the level, but also on the characteristics of additional costs, and on how they can vary according to the nature and severity of impairments.

The source of the cost of disability has been widely debated, in relation to social rights, not just economic well-being. A "medical model” addresses the cost of aids or treatments required to overcome the physical effect of a disability, focusing on the individual and his or her "impairment”. In contrast, the "social model of disability” (UPIAS 1975; Oliver, 1996) argues that costs arise not from the impairment itself but from the way society is organised, which disables individuals who have impairments. (The consequent costs can be both economic, in terms of expenditures required to overcome these disabling effects, and social or psychological, in terms of the wider disabling impact on the individual.) 
While there has been considerable criticism of the social model and how it has been applied or directed (eg Shakespeare and Watson, 2001; Allan 2010; Beckett and Campbell, 2015) there is wide agreement that "a social approach to disability is indispensable” (Shakespeare 2013: 220). In this context, a starting point in approaching the cost of disability is to ask what extra resources disabled people require in order to participate fully in society, and to investigate this from the point of view of disabled people themselves, since non-disabled people cannot judge where the divide between social exclusion and inclusion lies.

Importantly, this approach to measuring costs does not claim to address a central tenet of the social model, that society needs to change to create environments that are more enabling for people with given impairments. It looks rather at how they can be enabled through additional resources allowing them to function in existing environments. As one additional costs study involving disabled participants concludes:

“... participants appreciated that social attitudes and the world around them would take time to change, but argued that they required resources now in order to have the same opportunities to participate as their non-disabled peers. With sufficient resources, disabled people are better equipped to reduce or remove barriers until larger-scale societal changes take place.”

(Wilkinson-Meyers et al, 2014: 1551)

In this context, this article uses the term "cost of disability" to signify additional costs that people with given impairments must incur in order to reach an equivalent living standard to those without these impairments. (As elaborated below, “equivalent” does not necessarily mean living in an identical way, but rather at what could be considered the same level, with a focus in this article on a level considered in both cases to be the "minimum acceptable".) While differentiating costs according to people's specific impairments, we do not represent these costs as "the cost of impairment", since a cost can arise not only from the impairment itself but from ways in which society is organised.

The following section discusses various approaches to measuring the additional cost of disability and how they relate to different objectives. Section 3 then introduces the Minimum Income Standards approach. Section 4 describes how this MIS approach was applied in a study on the additional costs of sensory impairment, including methodological issues. Section 5 summarises the qualitative and quantitative findings that emerged (which are written up in 
more detail in Hill et al, 2015 and Hill et al, 2016). Section 6 suggests how this evidence can help shed light on the significance of different types of additional cost. Section 7 concludes by reflecting on what this method can contribute to the understanding of the additional costs faced by disabled people, complementing findings from other methods.

\section{Approaches to measuring additional costs}

At the broadest level, attempts to measure how much extra a household needs to spend as the result of a disability in order to attain a given living standard can be divided into two categories (Morciano et al, 2012), which can be labelled “equivalence-based” and “costsbased”. These approaches are very different methodologically, and each produces results that are helpful for a different purpose.

\section{Equivalence based approaches}

An economic approach to comparing costs starts by estimating household living standards, and then observes at what levels of income different household types achieve an "equivalent" standard of living. This allows an estimate of how much extra certain households need to spend compared to others, in order to be equally well off.

The most common method used by economists to compare household living standards in this process is to observe their expenditure patterns, knowing that poorer households tend to spend higher proportions of their income on food and other essentials (McClements, 1977; Banks and Johnson 1993; Wilke, 2006). To give a simplified example, if three-child families with income A are found on average to spend the same proportion on essentials as two-child families on a lower income, $\mathrm{B}$, this is held to imply that the former families reach the same living standard despite their higher incomes, because of the extra child, so the cost of the third child is inferred to be A minus B. Reporting of income distribution can be adjusted based on these different spending needs. However, such "equivalisation” is regarded as highly indicative given the imperfection of measuring what comprise "essentials” and in interpreting family choices over the distribution of their expenditure (Banks and Johnson 1993; Pollak and Wales, 1979). Jones and O’Donnell (1995) extended the spending-pattern method to a comparison of households with and without disabled people, showing that these costs are substantial.

Further equivalisation-type studies have sought to overcome the difficulty in observing consumption patterns by using other indicators of living standards. Some have relied on 
people's own subjective assessments of their well-being (Stewart, 2009). To consider the extra cost of disability, Zaidi and Burchardt (2005) used a combination of subjective indicators (how households report their financial situation), whether households possessed various consumer durables and whether they had savings. Morciano et al (2012) considered living standards in terms of “deprivation” - measured by looking at how many items considered as "necessities" by the general population that the household reportsit is unable to afford. They found that an older person above the median level of disability requires on average $£ 99$ a week more than an older person with median disability, well above that paid through benefits (see also Berthoud et al, 1993).

All these equivalisation approaches are useful in showing how poverty measures must take account of the additional needs of disabled people when using income comparisons to measure poverty. (They also allow consideration of the cost of disability to non-deprived households, who end up worse off than someone on the same income without such costs.) However, they have limitations. They focus on spending on general essentials, but do not take full account of disability costs that go unmet. For example, when measuring whether a household is deprived, Morciano et al (2012) consider whether households are unable to afford necessities such as buying shoes, but not whether in prioritising these essentials they are unable to afford additional items to meet the costs of disability - an integral aspect of whether a disabled person is deprived. Moreover, equivalence-based studies give broad estimates of the overall cost of disability, but do not specify how particular disabilities give rise to particular costs.

\section{Cost-based studies}

Studies of the specific cost of disability seek to provide a more direct account of what extra expenses disability brings. Two very different methods have been used to do so. One is to identify what disabled people actually spend on additional items - the "expenditure" approach. The other is to enumerate what needs to go into a household budget in order to meet additional household requirements - the "budget standards” approach.

The expenditure based approach asks households to identify actual expenditure related to disability, for example through detailed interviews with households exploring their additional costs (Large, 1991; Thompson 1990). Wood and Grant (2010) sought to answer similar questions through a larger-scale questionnaire based study to identify the range of additional spending that disabled people could identify. One issue for such studies is whether disabled 
people are able to identify what aspects of their expenditure are "additional” without having a clear-cut baseline of non-disabled people's spending. Another, in common with the equivalence based studies referred to above, is that they do not take account of unmet need: actual household spending is constrained by household income, and therefore will not always cover fully the additional needs that arise.

A budget standards approach, rather than looking at expenditure, considers what a household needs to spend in order to achieve a minimum acceptable living standard. A budget list comprising a minimum basket can be drawn up by experts or, in the case of a "consensual" method, by groups of member of the public. The latter approach aims to base a minimum on social consensus about necessities rather than on arbitrary expert judgements or on patterns of actual spending which do not take account of unmet need. Smith et al (2004) used a consensual method to ask groups of disabled people to identify additional costs faced by people with particular categories of impairment. Wilkinson-Meyers et al (2014 and 2015) built on this study and on Saunders et al.'s (1998) study of general budget standards in Australia, to explore additional needs for people with a range of disabilities in New Zealand. Their aim was to use a consensual method to integrate the social model of disability with an economic cost model, identifying the cost of additional support, equipment, travel and time required to achieve an adequate standard of living in the community (Disability Resource Centre, 2011).

A significant limitation in applying budget standards to disabled people's costs has been that estimates of additional costs are difficult to identify where there is no "baseline" of spending to compare them to. This is particularly limiting when considering different ways in which disabled people live their lives, not just the purchase of discrete items such as specialised equipment. In order to take all aspects of disabled people's lives into account, Smith et al asked disabled people to enumerate their overall living requirements and compared these to the average actual expenditure of non-disabled people - a highly imperfect solution. The study recognised the limitation of calculating disabled people's budgets without a directly comparable baseline for comparison (Smith et al, 2004, p20).Subsequent reviews of evidence on disability costs (Wood and Grant 2010; Morciano et al 2012) have questioned whether in this context additional costs can be reliably estimated through such a method. WilkinsonMeyers et al (2014 and 2015) did draw comparisons with a non-disabled budget standard to arrive at additional costs. However, they took a somewhat different approach, agreeing needs using experts and a reference group of disabled people to draw on prior evidence to draw up 
disability-related lists of resources, which were reviewed and revised by a focus group of disabled participants for each category under investigation. This method produced a range of insights into the nature of barriers faced by disabled people and how additional resources can help overcome them.

The remainder of this article looks at a new version of the consensual method which uses the now established Minimum Income Standard (MIS) as a baseline. The method involves groups of disabled people drawing up lists of items that those with given impairments would need in addition to items identified by non-disabled people in the same demographic categories. The MIS approach applies the “consensual” principle to identifying additional costs in a new way, which distinguishes it from the prior research described above: it has as a starting point decisions both about non-disabled and disabled people's requirements that are drawn up by groups of ordinary citizens in each of these categories, rather than asking citizens to comment on lists of items derived by experts (Wilkinson-Meyers et al 2015) or having to use expenditure data as a proxy for costs of non-disabled people (Smith et al 2004).

As well as allowing a stronger decision-making role for the citizen groups, comparison with a non-disabled baseline offers a more focused account of exactly what needs are additional. It also allows detailed comparisons between the needs arising from different levels and categories of impairment, and insights into what categories of need are driving these differences.

\section{A minimum income standard for disabled households}

The Minimum Income Standard has been chosen as an approach to measuring the additional costs of disability because it allows a tangible account of people's needs which derives from the expertise of those who experience life with the impairments under review. The method (Bradshaw et al, 2008; Davis et al, 2015) is based on detailed compilation of minimum household budgets by deliberative groups comprising members of the public, mainly using a consensual budgets method, with input from experts on just a few aspects such as nutritional standards and energy consumption. Through a series of groups, a consensus is reached about what should be included in the budget of a specified household, in order to reach a minimum acceptable standard of living. This is defined as “...including but more than just food, clothes and shelter: it is about having what you need in order to have the opportunities and 
choices necessary to participate in society”. The standard is regularly updated, through price adjustments and through new waves of research tracking changes in contemporary requirements. This research has demonstrated that detailed and iterative consultation with groups of members of the public can define the minimum essential goods and services required for life in the home and for social participation. It is supported by strong and consistent rationales, and a high degree of consistency in what this includes, across demographic categories and across time (Davis et al, 2015).

Using the minimum budget of a given household type (such as a single person living on their own) as a baseline, this method has also been used to explore additional or different needs of people in particular types of situation, including those in remote rural locations (Smith et al, 2010; Hirsch et al, 2013); those in London in contrast to other parts of the United Kingdom (Padley et al, 2015) and those with foster children (Davis and Padley, 2013). Looking at additional needs and costs involves a succession of three revising groups for each household case. The first group starts with the main MIS budget lists and considers whether and how each area of the budget needs to be revised for the variation in question - for example, whether someone living in a remote location would require different transport, shopping and leisure patterns to those specified in the main budget. The remaining two groups then consider whether they agree with such revisions and whether others need to be made. As a whole, the research identifies where there is a general consensus across groups that the budgets need to be adapted in a particular way. Where there is no such consensus, the budget for the new case is left unchanged. This allows additional costs to be calculated, but only where there is clear agreement that they are warranted.

The same approach has been extended to identify the additional cost of disability for someone with a given impairment. Groups comprising people with an impairment and household situation similar to those being considered are asked to identify additional needs and costs based on an imaginary case study. This creates a careful and meaningful description of how someone with these characteristics could live at a minimum acceptable level. Rather than considering the need for each item in isolation, the method builds up a picture of the case study's living patterns. Thus, for example, social participation and shopping practices can be related to means of travel and mobility requirements. By starting with what is already established as required by a non-disabled household, groups are able to identify which areas of spending need to be different and which would be the same. 


\section{Two MIS studies exploring the needs of individuals with sensory impairments.}

In 2014 and 2015, funded by Thomas Pocklington Trust, the MIS team at Loughborough University carried out two studies, between them looking at four different examples individuals living alone with a particular sensory impairment, to identify the additional costs that each would experience using the method described in the previous section (Hill et al, 2015 and 2016). The cases covered individuals:

- of working age, sight impaired*, with some usable sight;

- of working age, severely sight impaired*, with little or no sight;

- of pension age, with sight impairment* acquired in adult life, and some usable sight; and

of working age, profoundly deaf and using British Sign Language

*In this context sight impaired means eligible for certification as sight impaired, and severely sight impaired means eligible for certification as severely sight impaired. The term vision impaired is used below to refer to either case and sight loss more generally.

In the case of vision impairment, the two working-age examples allow a comparison of the costs experienced at different levels of severity, while the examples of the same level of impairment among working age adults and pensioners allows comparison of the effects at different life stages. Although the studies were funded by a sight loss charity, the inclusion of a profoundly deaf case study allows for further exploration of a different type of sensory impairment.

In each of these case studies, the example considered was of a single person living alone. In this first research applying the MIS method to the cost of disability, this helped highlight additional needs experienced by individuals living with an impairment, without at this stage introducing the complicating issue of how much extra assistance might be provided by others living in the household. The advantage of this approach is that it does not take for granted that another household member will be available to provide assistance, and thus is a purer measure of the cost of disability. It could be possible in future to consider the case, say, of someone who lived with a partner, but this would require consensus being reached about the extent that one could expect to get help from a partner and in what respects it is important to be able to function independently in order to maintain dignity. (It would also be important, in assessing the ways in which disabled people benefit from support from other household 
members, to take account of how disabled people in turn contribute to meeting household needs, rather than seeing "support” as a one-way process.)

The two studies successfully assembled twelve groups, each with five to nine participants and lasting around five hours over the course of a day. In each case they carried out discussions in the same style as the main MIS groups, with the aim to identify a prevailing consensus within and across groups about where there would be different and additional needs and costs compared to the non-disabled budget. Deaf groups were supported by British Sign Language interpreters and both vision and hearing impaired groups were run in ways sensitive to their communication needs. Groups took place in urban locations in England; as with the main MIS research, it is recognised that the needs of people with sensory impairment living in rural locations may vary. Nine of the groups involved participants aged 18-64 and three aged 65 and over. Participants were drawn from a range of socio-economic backgrounds; about three in five were women and about one in five were non-white. As qualitative research, this study does not seek to present the views of a nationally representative sample of the relevant population, but brings together groups of participants from a range of backgrounds but with similar sight or hearing impairment in common to focus on the additional costs of the particular impairment in question. .

An important requirement of this research is that, even though participants come from the household types whose needs are under consideration, they are not behaving as advocates but as "experts" in what life is like for the type of household in question. This is a requirement of all MIS groups and it was important for this research to ensure that participants were recruited with this in mind. In order to reach a range of people with everyday experience of living with the particular impairment, recruitment took place both through advertising via national sight loss networks (such as through email circulars and newsletters) and by approaches to people using service centres, support networks and social clubs, often through local level organisations or contacts. Furthermore, the mediation of groups is designed to ensure that participants are focused on the needs of an imaginary individual (a case study is used), not what they consider necessary for themselves. In discussion about what items to include, participants are asked to say what makes them necessities - a 'need rather than nice to have' - creating a clear rationale for their decisions.

One important feature of the MIS research on additional needs for disability is that the discussion is not framed in terms of how a disabled person can live exactly like a non- 
disabled person, or require that expenditure on additional goods and services should effectively neutralise the effect of disability. As discussed at the start of this article, a calculation of how additional resources can help disabled people participate in society addresses only part of the solution suggested by the social model of disability, which also requires society to change. In this context, an over-literal interpretation of how a "level playing field" can be achieved in the world as it is today can produce results that are not helpful in describing a socially agreed minimum, because they are so remote from current reality. Smith et al (2004, p53) found that when asking deaf people what was needed to produce a level playing field for people who were profoundly deaf by giving them identical access to services and opportunities for social engagement as hearing people, they pointed out that this would require an interpreter operating like a personal assistant (for 40 hours a week). This led to the finding in this study that a deaf person needed to spend $£ 1336$ a week in 2004, nearly three quarters of it on interpreter services.

In the present studies, participants were not asked what people need for a level playing field, but what they need for a minimum acceptable living standard in the context of society today. This research defined minimum in the same way as in the main MIS research to produce an equivalent concept, without suggesting that equivalence implies an identical lifestyle. In this context, participants came up with their own view about what someone with the particular impairment under review would need in order to have a lifestyle that they felt met their minimum needs including for social participation. This included different ways of taking account of their impairment. For example, for someone who is profoundly deaf it included a modest amount of paid interpreter support for interactions with services where free interpretation is not available, and additional money for more frequent social participation. People who are vision impaired included extra money to allow someone to 'treat' a friend who might give assistance when accompanying them on certain occasions, and for additional travel to maintain social networks. These models accept that there are additional needs for social participation, but frames them in the real patterns of hearing or vision impaired people’s lives, rather than seeking to replicate precisely the lifestyle of a non-disabled person.

A related issue for this research is how to treat additional needs that might be covered by any service supplied directly, free or at discounted charge, by a public body. A fuller account of costs associated with disability would include additional expenses regardless of who bore them, but budget standards explicitly address only the private cost to households, and hence minimum household income requirements. This requires assumptions to be made about how 
much is covered by public bodies, in order to establish which costs fall on households. Groups in MIS are asked where necessary to state such assumptions, based on prevailing norms of provision. It is accepted, however, that such provision may in practice vary by area and can change over time. MIS cannot therefore describe all situations, but by making its assumptions explicit, it allows supplementary calculations of how much difference the addition or removal of a form of public provision can make to private costs.

\section{Main findings}

The studies described in the previous section identified consensus among groups of vision impaired and profoundly deaf people about a number of additional costs that single people in the four categories described above would need to cover in order to maintain a minimum acceptable standard of living. Table 1 enumerates these costs, classified by spending category. 
Table 1 Minimum household budgets for people with sensory impairments: results

\begin{tabular}{|c|c|c|c|}
\hline \multicolumn{4}{|c|}{$\begin{array}{l}\text { a) Minimum weekly budget, for a single person who is vision impaired (excluding } \\
\text { rent; } 2014 \text { prices) }\end{array}$} \\
\hline \multirow{2}{*}{$\begin{array}{l}\text { Main MIS standard budget (without } \\
\text { disability): }\end{array}$} & \multicolumn{2}{|l|}{ Working age } & \multirow{3}{*}{ 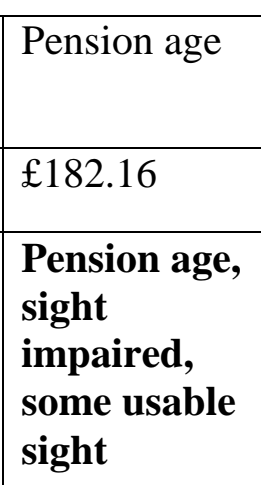 } \\
\hline & \multicolumn{2}{|l|}{$£ 195.29$} & \\
\hline $\begin{array}{l}\text { Additions for a person who is vision } \\
\text { impaired }\end{array}$ & $\begin{array}{l}\text { Working age, } \\
\text { sight } \\
\text { impaired, } \\
\text { some usable } \\
\text { sight }\end{array}$ & $\begin{array}{l}\text { Working age, } \\
\text { severely sight } \\
\text { impaired, } \\
\text { little or no } \\
\text { usable sight }\end{array}$ & \\
\hline Household services & $£ 13.46$ & $£ 30.71$ & $£ 26.32$ \\
\hline Transport and travel & $£ 6.50$ & $£ 27.50$ & $£ 24.17$ \\
\hline Social activities & $£ 8.98$ & $£ 19.28$ & $£ 5.91$ \\
\hline Technology & $£ 12.82$ & $£ 18.11$ & $£ 6.21$ \\
\hline Food and drink & $£ 0.00$ & $£ 9.23$ & $£ 5.70$ \\
\hline Personal goods and services & $£ 3.27$ & $£ 6.91$ & $£ 2.04$ \\
\hline $\begin{array}{l}\text { Household fittings, furnishings and } \\
\text { selected household goods }\end{array}$ & $£ 3.18$ & $£ 3.96$ & $£ 4.73$ \\
\hline Household bills & $£ 0.56$ & $£ 0.73$ & $£ 0.32$ \\
\hline Total additions & $£ 48.77$ & £116.43 & $£ 75.39$ \\
\hline Total weekly budget & $£ 244.06$ & $£ 311.72$ & $£ 257.55$ \\
\hline \multicolumn{2}{|c|}{$\begin{array}{l}\text { b) Minimum weekly budget for a single working } \\
\text { age person who is profoundly deaf (excluding } \\
\text { rent; } 2014 \text { prices) }\end{array}$} & & \\
\hline $\begin{array}{l}\text { Main MIS standard budget (without } \\
\text { disability) }\end{array}$ & $£ 195.29$ & & \\
\hline \multicolumn{2}{|l|}{$\begin{array}{l}\text { Additions for a person who is } \\
\text { profoundly deaf: }\end{array}$} & & \\
\hline Interpreter & $£ 126.58$ & & \\
\hline Social activities and holiday & $£ 22.79$ & & \\
\hline
\end{tabular}




\begin{tabular}{|l|l|}
\hline Technology & $£ 6.10$ \\
\hline Travel & $£ 5.43$ \\
\hline $\begin{array}{l}\text { Other: (electricity, spare hearing aid } \\
\text { batteries, burglar alarm, miscellaneous) }\end{array}$ & $£ 2.13$ \\
\hline Total additions & $\mathbf{E 1 6 3 . 0 3}$ \\
\hline Total weekly budget & $\mathbf{E 3 5 8 . 3 2}$ \\
\hline
\end{tabular}

Source: Hill et al $(2015 ; 2016)$

The first column of Table 1 shows that for a working age person who is sight impaired with some usable sight, additional costs add 25\% to the main MIS budget for a non-disabled person and are spread across a wide range of categories, with no one category dominating. Some of the additional costs arise from the purchase of specialist equipment, mainly assistive technology, such as IT software or an electronic magnifier. Other costs are for items already included in the main MIS budget but that cost more because their specification is changed in relation to sight impairment, such as a computer with a larger screen, a higher grade television that provides menus with a voice guidance option or a higher quality mobile phone, which was considered more accessible. However, the average weekly cost of paying for such items comprises only part of the total cost of vision impairment, with most of it coming from recurring weekly expenses concerned with day to day living. For example, there was consensus that someone who was sight impaired would need some help with keeping their home clean, and even though this amounted to just two hours a fortnight, the weekly cost of $£ 12.50$ was the single largest additional item. Other additional costs linked to day to day living include additional travel costs such as paying for taxis and more expenses linked to social participation, including recognising the help given by friends by treating them to the occasional meal, drink or ticket.

"I always feel obliged if I ask someone to come with me to give them something in return because I feel like I'm really needy.”

(Sight impaired working age group)

As shown in the second and third columns of Table 1, both a more severe degree of impairment and being a pensioner rather than a working-age adult add substantially to the 
cost of vision impairment outlined in the first case. In both cases, these further costs come mainly from additional services. In particular, both older sight impaired people and those of working age with severe sight impairment say they need more help in the home. This includes extra cleaning costs for larger or more detailed tasks and help with paperwork, which were not included in the working age sight impaired budget. Both of the transport budgets were also increased to cover more spending on taxis because public transport can be harder to access. This was for practical reasons, for example getting to appointments and support networks, but also related to confidence, such as making journeys in the evenings or on unfamiliar routes, and for pensioners linked to the combination of sight impairment and reduced mobility associated with sight loss and age.

“Woman (W): I haven’t been on a bus for about two years because I am frightened of falling with the step. I can’t gauge how high the step is. And really it bothers me so I don't....It is my lack of confidence because of the vision. It is very awkward, I can't explain it, but I can’t visualise the depth at all.

W: ...I am frightened to death of falling on the bus. And you don't have time to sit down before they are off.

W: That's true...

$\mathrm{W}$ : ...the bus route coming back to the main road is very slow, very busy and she might not feel safe even sitting on that bus because it is so crowded and there are so many people moving in and out and she might have someone come and plonk themselves down by the side of her on the bus and then wonder after they had gone whether she had had her purse in her shopping bag, her handbag or zipped into her pocket, So she might feel safer in a taxi.”

(Sight impaired pension age group)

This linking of the additional cost of taxis with how confident vision impaired people feel using buses raises the question of how far such costs are an avoidable product of inadequately accessible bus provision. The Equality Act (2010) requires service providers to make "reasonable adjustments" to overcome barriers experienced by disabled people, and further adjustments could allow a vision impaired person to feel confident enough to take a bus. However, a further benefit of taxi travel was the convenience of door to door transport 
which was important in some circumstances and not possible no matter how accessible the bus service.

Severely sight impaired working age adults specify a substantially higher social participation budget to allow for more activities, associated with their perception that they need additional resources to combat the risk of social isolation which is greater with a more severe condition. Higher additional technology costs for this group relate in particular to greater demands placed on the computer and mobile phone requiring a higher specification and/or more frequent replacement of these items. More severe sight impairment requires more focus on computer speech software, and the heavier use of the phone as a multi-use item (see further below). The need of someone with little or no sight is to replace rather than enhance vision, and for working age people technology can play a crucial role. Another difference observed in Table 1 is that the food budgets are affected by severity and age. Both working age severely sight impaired and pension age sight impaired groups felt that it can be more difficult and time consuming to prepare food, and felt it was reasonable to include some preprepared meals and ingredients which had not been added in the sight impaired working age person's budget.

A further example, shown in the second part of Table 1, is of someone at the more severe end of hearing impairment - a person who is profoundly deaf and for whom BSL is the main communication. In this case the costs are substantially higher due to the need for a specialised form of one to one assistance: an interpreter for a modest amount of time (see above) - agreed at ten hours a month. This comprises most of the additional costs for a profoundly deaf person, which overall adds over 80 per cent to the main MIS minimum weekly budget for a single person without a disability. The other items identified include a few technological items, in particular a higher grade mobile phone than is needed as a minimum by a hearing person, to provide a good quality and reliable means of communicating via sign language. As with the sight impaired case these costs are relatively small. More significant are costs associated with additional social participation and travel, which stem mainly from the view that a someone who is profoundly deaf living on their own should be able to get out more frequently than a hearing person, in order to avoid the risk of isolation. As one group participant explained:

“Don’t forget, if he’s deaf it’s very easy to get very stressed at home. He’s very isolated, so you do want to go out.” 
These selected examples of the many impairments and living situations that disabled people face show how the minimum cost of living can be substantially higher for a disabled person. This article has provided some examples of how these costs can vary and how costs can arise from a variety of aspects of life and not just from dealing directly with the physical consequences of disability through additional equipment or home adaptations. The following section discusses further what can be learned from these results.

\section{The cost of disability in a social perspective: discussion}

This investigation of what specific additional goods and services disabled people judge to be needed in order to have an acceptable living standard has produced a wider perspective than would be obtained just by focusing on meeting needs arising directly from particular impairments. In particular, it has shown how costs relate to how people live their lives and interact in society.

Previous analysis has sought to classify additional costs in various ways. For example, Tibble (2005 pp5-6) distinguishes costs that are "special” to disabled people or "additional” items of a non-specialised nature; whether they are "one-off” or "recurrent”, whether they are “direct” or "indirect” and whether "potential” or “realised”. Wood and Grant (2010), build on the first of these distinctions, distinguishing within "additional" costs those that required extra consumption from those that simply cost more (like a higher insurance premium).

The research reported here confirms that the specialised/non-specialised and recurrent/oneoff nature of costs has great salience to the overall cost of disability and how it might be mitigated. By talking to disabled people about their everyday lives, it has also shown how recurrent costs covering day-to-day living can be a more important part of the overall cost of disability than has been picked up in questionnaire based surveys, which more readily focus on costs relating to tangible items, such as equipment, rather than to ways of living. This study's emphasis on the importance of travel, personal support and other day-to-day living costs corroborates the quantitative conclusions of Wilkinson and Meyers et al (2015), who also attribute more of the cost of disability to support services and transport than to purchase of equipment (p987).

It may be helpful in this context to think of a distinction between things that disabled people need to have and those that that they need to do (the latter including the cost of any help they 
require in doing these things). Items that disabled people need to have, ranging from a wheelchair for someone unable to walk to a magnifying glass for someone who is vision impaired, typically incur costs on an occasional basis rather than week to week - although some needs such as an adapted diet will require more regular expenditure. For costs incurred only very infrequently such as home adaptations, the average weekly cost over a long "lifespan" is often modest. The vision impaired groups participating in the study described above did identify some equipment needed as a minimum for people with these conditions, but the cost, spread over time, produced relatively small weekly amounts. Even the one case of a very expensive purchase - a refresher Braille display for use with a computer costing $£ 1885$ (part of a supplementary calculation of the needs of people using Braille) - the cost averaged at a relatively modest $£ 5.26$ a week over the anticipated lifetime of the item. One needs of course to acknowledge that although this does not have big implications for recurrent income requirements, finding the money for such a large one-off purchase will not be easy for people on low incomes. Moreover, even the average weekly cost of equipment will not always be low: for some groups requiring expensive equipment such as wheelchairs it is likely to be substantially higher than the cases looked at here. However, it is notable that both working age vision impaired and profoundly deaf groups pointed to how technologies in common use have developed in ways that can sometimes assist people who are vision or hearing impaired in cheaper and more convenient ways than through the more specialised products of the past. For example an iPhone was viewed by profoundly deaf people in this research as necessary for signed communication and a home Minicom was not included in the budget. Likewise an iPhone was regarded as a multi use item by working age vision impaired groups in the research, particularly so for those severely sight impaired - this included tools and apps for magnification, screen reader, dictation, assistance, scanning, GPS and playing music.

"Man (M): [the mobile phone] is a mini computer basically...

M:...getting here today I was walking thinking I know I'm going the wrong way, I know this is the wrong way. So on the phone I went 'where am I?' and it says you're on the corner of xxx Street, that means I know I'm within a few metres.” 
This reflects Jewell and Atkin's (2013) observation that advances in mainstream devices with improved accessibility features that can be adapted and used as enabling technology could sometimes lessen the need for more expensive standalone equipment.

The size of costs associated with what disabled people $\boldsymbol{d o}$ in everyday life are determined by a very different set of factors to the cost of what they have. For both the vision impaired and profoundly deaf cases, the former was found to account for the majority of additional costs. In the case of the vision impaired person, these needs included using taxis, help in the home, the treating of a friend who has assisted one with a social activity and additional charges associated with different telecommunications needs (including for example higher data usage associated with using certain applications). These were all costs incurred on an ongoing basis, which this study also shows can vary by severity of impairment and by life stage, explaining why even relatively small expenditures could produce more spending overall than most occasional or infrequent purchases (when costed over time).

The key dimension that influences the additional cost of services and support for what disabled people do is the extent to which disability requires individualised assistance. This can be seen as a continuum rather than a dichotomy. The most expensive services are those giving frequent one to one help, such as personal assistance. If in addition this is a specialised service, it can dwarf the scale of all other costs -as shown in the example of interpreters above. Another less specialised service such as a regular taxi journey or a cleaner for one's home may add smaller but still significant expense due to the fact that it requires the engagement of an individual's labour, albeit for a relatively small amount of time each week. Informal support can bring "hidden" costs such as the need to treat a friend to a drink or meal as a "thank you” for assistance in social activities or for help with dealing with paperwork. These are not seen as labour costs but can still be significant when incurred regularly. Other services, such as more expensive mobile phone packages to meet particular needs, may also bring regular but more modest costs.

It is important to note that the finding that most additional costs come in this second broad category of supporting everyday life rather than purchasing equipment may apply to people who are vision impaired or profoundly deaf, but cannot be generalised across disability types. Nevertheless, this initial study produces the important observation that an image of disability costs focused on providing specialised equipment like wheelchairs, hearing aids or expensive forms of assistive technology only gives part of the picture - and for some disabled groups 
quite a small part. Many costs are much more indirect, and relate to how a disabled person lives, not to aids designed to help cope with a disability.

A further, crucial finding emerged from the second of the two studies reported here (Hill et al 2016), which looked at how costs of vision impaired people vary according to impairment severity and age. Many of the differences identified related to an interaction between practical aspects of living with vision impairment and psychological factors including sense of confidence and of vulnerability. An example of this is that older people with acquired sight loss and working age people with little or no usable sight noted more practical difficulties but also felt less confident in using public transport and therefore specified a higher taxi budget than sight impaired working age people with some usable sight.

These overall findings that many costs of disability are influenced by the ways disabled people interact in society, which can vary according to both practicalities and people's level of confidence and vulnerability, pose serious challenges for the assessment of eligibility for public help in covering these costs. Recent studies have found that the introduction of Personal Independence Payments (PIPs) in the United Kingdom, to replace the Disability Living Allowance with support assessed on a points system of what people can and cannot do, in practice fails to promote independence but rather aims to narrow criteria for support (Roulstone, 2015; Ellis et al, 2015). Roulstone suggests for example that the criterion of not being able to walk more than 20 metres unaided is restrictive not just because it is more severe than a previous 50 metre threshold, but also because such narrow physical criteria "fail to account for social barriers”. The research reported on in this article (Hill et al (2015, Hill et al, 2016) supports the conclusion that PIPs are ill-adapted to recognising the extent of additional costs of the type identified in this study, because eligibility relates only to narrow descriptions of what people can do, not to how they live.

As well as the issue of assessment, a further policy issue that this raises concerns the flexibility with which disabled people can use resources from the state designed to help cover additional costs. Use of disability benefits such as Disability Living Allowance has always been flexible, and the deployment of support for social care has also become more flexible under direct payments and personal budgets. However, as was shown when use of the Independent Living Fund was curtailed only to cover approved tasks, there remains a tension between the importance of autonomy and the need to show that help is being used for things that the public would regard as legitimate (Duffy et al, 2010 pp503-504). Evidence from the 
kind of research reported on here, by demonstrating that for disabled people to participate fully in society they may need to spend extra money on a range of items that include more than just physical aids and personal care, can help legitimise support that is narrow neither in the assessment of entitlements nor in the authorised uses to which it is put.

\section{Conclusion}

The measurement of additional costs to households resulting from disability is essential to inform welfare systems and the measurement of poverty, but there is no single method that captures these additional costs perfectly. This article has shown how qualitative, detailed assessment of costs arising from specific disabilities can complement more quantitative, generalised surveys of the relationship between income, disability and living standards. Such qualitative assessments can directly address questions raised by the social model of disability about how additional resources can help enable people with given impairments to participate in society, and answer those questions from the perspective of disabled people themselves.

The Minimum Income Standards method produces a more robust basis for using budget standards for this purpose than was previously available. It provides a baseline of costs that do not account for disability, but allows an assessment of what is "additional”, and offers a well-tried and stable method for building consensus among groups with experience of a particular household situation about what comprises a minimum acceptable standard of living.

The application of this method has so far been trialled only for a limited number of cases of people with sensory impairments, but has shown the potential for extending it to other types of disability. The evidence so far suggests that costs can be far more heterogeneous than may be assumed by a model of need based on narrow aspects of physical functioning, which often inform assessments for benefit eligibility. This reinforces the importance of assessing costs in relation to how people participate in society, and of using the experience of disabled people to produce evidence for what additional costs this imposes. Policy making that genuinely seeks to promote active and independent lifestyles among disabled people, will need to understand the cost of disability in this wider context.

\section{References}

Allan, J. 2010. “The Sociology of Disability and the Struggle for Inclusive Education.” 
British Journal of Sociology of Education 31 (5): 603-619.

Banks, J. and Johnson, P. (1993) Children and household living standards, London: Institute for Fiscal Studies.

Beckett, A. and Campbell.T. (2015) The social model of disability as an oppositional device, Disability \& Society, 30:2, 270-283, DOI: 10.1080/09687599.2014.999912

Berthoud, R., J. Lakey, and S. McKay. (1993) The Economic Problems of Disabled People, Policy Studies Institute, London.

Bradshaw, J., Middleton. S., Davis, A., Oldfield, N., Smith, N., Cusworth, L. and Williams, J. (2008), A minimum income standard for Britain - What People Think, York: Joseph Rowntree Foundation.

Corden, A, Sainsbury, R, Irvine, A and Clarke, S (2010). The impact of Disability Living Allowance and Attendance Allowance: Findings from exploratory qualitative research, DWP Research Report No. 649, London: HMSO.Davis, A. and Padley, M. (2013) Household Costs and Foster Care. Loughborough: Loughborough University.

Duffy, S., Waters, J. and and Glasby, J. (2010), Personalisation and adult social care: future options for the reform of public services Simon Duffy, John Waters and Jon Glasby, Policy \& Politics vol 38 no 4, 493-508

Ellis, L., Douglas, G. and Clarke, H. (2015) Experiences of Personal Independence Payments (PIP) for People with Sensory Loss, Research Findings 48, London, Thomas Pocklington Trust.

Davis, A., Hirsch, D. and Padley, M. (2015) How much is enough. Reaching social consensus on minimum household needs. Loughborough: Centre for Research in Social Policy

Disability Resource Centre (2011), The Cost of Disability - Final Report, Auckland: Disability Resource Centre. 
Hill, K., Davis, A., Hirsch, D., Padley, M., and Smith, N. (2015) Disability and minimum living standards: The additional costs of living for people who are sight impaired and people who are Deaf, Loughborough: Centre for Research in Social Policy.

Hill, K., Marshall, L., Hirsch, D. and Padley, M. (2016) Sight Loss and Minimum Living Standards:The Additional costs of Living for People of Working Age who are Severely Sight Impaired and for People of Pension Age with Acquired Sight Impairment Loughborough: Centre for Research in Social Policy.

Hirsch, D. (2015), A minimum income standard for the United Kingdom in 2015, York: Joseph Rowntree Foundation.

Hirsch, D., Bryan, A., Davis, A., Smith, N., Ellen, J. and Padley, M. (2013) A minimum income standard for remote rural Scotland. Inverness: Highlands and Islands Enterprise. Jewell, S. and Atkin, R. (2013) Enabling Technology, London: Scope.

Jones, A., and O’Donnell, O. (1995). Equivalence scales and the costs of disability. Journal of Public Economics, 56(2), 273-289.

Large, P. (1991), "Paying for the cost of disability” in Dalley (ed), Disability and social policy London: Policy Studies Institute.

MacInnes, T., Tinson, A., Gaffney, D., Horgan, G. and Baumberg, B. (2014), Disability, long-term conditions and poverty, York: Joseph Rowntree Foundation.

McClements, L. (1977) ‘Equivalence scales for children’. Journal of Public Economics, Vol 8, pp191-210.

Morciano, M, Hancock, R and Pudney, S (2012) Disability costs and equivalence scales in the older population ISER working paper 2012-09, University of Essex.

Oliver, M. (1996) Understanding disability: from theory to practice, Basingstoke: Macmillan.

Pollak, R. A., and Wales, T. J. (1979) Welfare comparisons and equivalence scales. The American Economic Review, 69(2), 216-221.

Roulstone. A. (2015) Personal Independence Payments, welfare reform and the shrinking disability category, Disability \& Society, 30:5, 673-688, DOI:

0.1080/09687599.2015.1021759. 
Saunders, P., J. Chalmers, M. McHugh, C. Murray, M. Bittman, and B. Bradbury. (1998) Development of Indicative Budget Standards for Australia. Report prepared for the Commonwealth of Australia. Social Policy Research Centre, University of New South Wales.

Shakespeare, T. (2013). The social model of disability, in Davis, L. (ed) Disability studies reader, fourth edition, London: Routledge.

Shakespeare, T., and N. Watson. 2001. “The Social Model of Disability: An Outdated Ideology?” Research in Social Science and Disability 2: 9-28.

Smith, N., Middleton, S., Ashton-Brooks, K., Cox, L. and Dobson, B. (2004) Disabled people's costs of living: more than you would think York: Joseph Rowntree Foundation.

Smith, N., Hirsch, D. and Davis, A. (2010). A minimum income standard for rural households. York: Joseph Rowntree Foundation.

Stapleton, D., Protik, A., and Stone, C. (2008). Review of international evidence on the cost of disability. Department of Work and Pensions research report 542.

Stewart, M. B. (2009). The estimation of pensioner equivalence scales using subjective data. Review of Income and Wealth 55(4), 907-929.

Thompson, P, Lavery, M, and Curtice, J (1990) Short-changed by Disability London: Disability Income Group.

Tibble, M, (2005) Review of Existing Research on the Extra Costs of Disability, London: Dept for Work and Pensions.

UPIAS (Union of the Physically Impaired Against Segregation) (1975) Policy statement, cited in Shakespeare, 2013.

Wilke, R. (2006) 'Semi-parametric estimation of consumption-based equivalence scales: the case of Germany’, Journal of Applied Econometrics, Vol 21, pp 781-802.

Wilkinson-Meyers, Laura, Paul Brown, Jeanne Reeve, Rob McNeill, Philip Patston, Sacha Dylan, Ronelle Baker, Bernadette Ryan \& Julianne McEldowney (2014) Reducing disablement with adequate and appropriate resources: a New Zealand perspective, Disability \& Society, 29:10, 1540-1553, DOI: 10.1080/09687599.2014.966803. 
Wilkinson-Meyers, Laura, Paul Brown, Rob McNeill, Jeanne Reeve, Philip and Ronelle Baker (2015) To live an ordinary life: resource needs and additional costs for people with a physical impairment, Disability \& Society, 29:10, 30:7, 976-990, DOI:

10.1080/09687599.2015.1061479.

Wood, C. and Grant, E. (2010), Counting the cost, London: Demos.

Zaidi, A., and Burchardt, T. (2005). Comparing incomes when needs differ: Equivalization for the extra costs of disability in the UK. Review of Income and Wealth, 51(1), 89-114. 